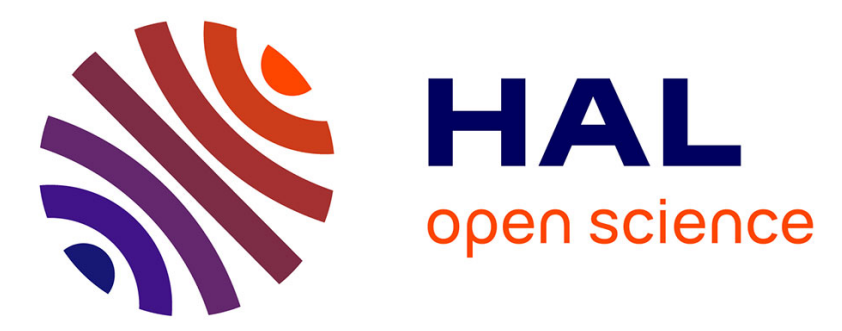

\title{
Optical measurements of phase transition and temperature in adiabatic shear bands in titanium alloys
}

Nicolas Ranc, Vincent Pina, Hervé Pasqua

\section{To cite this version:}

Nicolas Ranc, Vincent Pina, Hervé Pasqua. Optical measurements of phase transition and temperature in adiabatic shear bands in titanium alloys. Journal de Physique, 2000, 10 (9), pp.347-352. 10.1051/jp4:2000958 . hal-00283390

\section{HAL Id: hal-00283390 \\ https://hal.science/hal-00283390}

Submitted on 17 Apr 2018

HAL is a multi-disciplinary open access archive for the deposit and dissemination of scientific research documents, whether they are published or not. The documents may come from teaching and research institutions in France or abroad, or from public or private research centers.
L'archive ouverte pluridisciplinaire HAL, est destinée au dépôt et à la diffusion de documents scientifiques de niveau recherche, publiés ou non, émanant des établissements d'enseignement et de recherche français ou étrangers, des laboratoires publics ou privés. 


\title{
Optical measurements of phase transition and temperature in adiabatic shear bands in titanium alloys
}

\author{
N. Ranc, V. Pina and P. Hervé \\ Laboratoire d'Énergétique et d'Économie d'Énergie, Université Paris $X, 1$ chemin Desvallières, \\ 92410 Ville-d'Avray, France
}

\begin{abstract}
Adiabatic shear bands may occur in different type of solicitation such as high speed torsion, compression, and ballistic impact. The formation of a shear band is often an immediate precursor to rupture of the material. Fast localised temperature's gradient results from this plastic deformation. In order to generate adiabatic shear bands, we have built a dynamic punching device. We determine the temperature and the transition phase by optical measurement. A measure at two wavelengths allows us to dissociate the temperature and the emissivity. A measure at $0,6 \mu \mathrm{m}$ leads to the temperature in shear band and a measure at $5 \mu \mathrm{m}$ leads to the emissivity variation of the material and allows to identify the phase transition. The experimental results obtained for TA6V have enabled us to point out the existence of very high temperatures $\left(T_{\max } 1273{ }^{\circ} \mathrm{C}\right)$ within the shear band. We compare the emissivity variation of two titanium alloys (The TA6V and the Ti20V) and we detect the $\alpha \rightarrow \beta$ phase transition in the case of the TA6V alloy.
\end{abstract}

\section{INTRODUCTION}

Narrow bands of intense shear strain are often observed on materials submitted to high strain rates. In metals a large proportion of plastic deformation energy is converted into heat in the material. In dynamic solicitation there may not be enough time for the heat to diffuse away from the deformed zone. This type of phenomenon is also called adiabatic shearing. The consequence of this effect is the local growth of the temperature and a thermal softening of the materials. This phenomenon describes a catastrophic process which produces the failure of the structure.

Metallurgical studies of post mortem specimen show that the widths of adiabatic shear bands are between 10 and $100 \mu \mathrm{m}$ [1] and give us the composition of these bands. Phase transitions have not been identified during the study of the metallurgical composition in the centre of the band [2].

Taking into account the low size of the shear bands and the short duration of the phenomenon (the duration of the growth of temperature is around 10-20 $\mu$ s), it's very difficult to take measurements during the phenomenon.

In this paper we present a method to determine the temperature in the band and the phase transition during the phenomenon. We study the particular case of two titanium alloys: the TA6V and the Ti20V.

\section{EXPERIMENTAL STUDY}

\subsection{Solicitation device}

To reproduce adiabatic shear bands and obtain high strain rates, we designed a new punching device. It is composed of a compressed air gun and a vice soliciting a parallelepipedic specimen in double shear (width: $10 \mathrm{~mm}$, thickness: $2 \mathrm{~mm}$, length: $40 \mathrm{~mm}$ ). 
The vice is composed of two jaws (superior and inferior) and a punch, which solicits the specimen in double shear (Figure 1). This device ensures the embedding of the specimen by tightening of the jaws and eliminates to the maximum the inflection solicitation in the specimen. Thanks to the design of the vice we can visualise the shear zones in order to make thermographic measurements.

To carry out a dynamic stress, a projectile $(2 \mathrm{~cm}$ in diameter and a $7 \mathrm{~cm}$ length) is launched by a compressed-air gun on the punch. Speeds of projectile obtained vary around $50 \mathrm{~m} / \mathrm{s}$. It is measured using two photodiodes, which give us the time of passage of the projectile on the level of two infrared beams. Knowing the distance between the two diodes, the speed of the projectile can be determined easily.
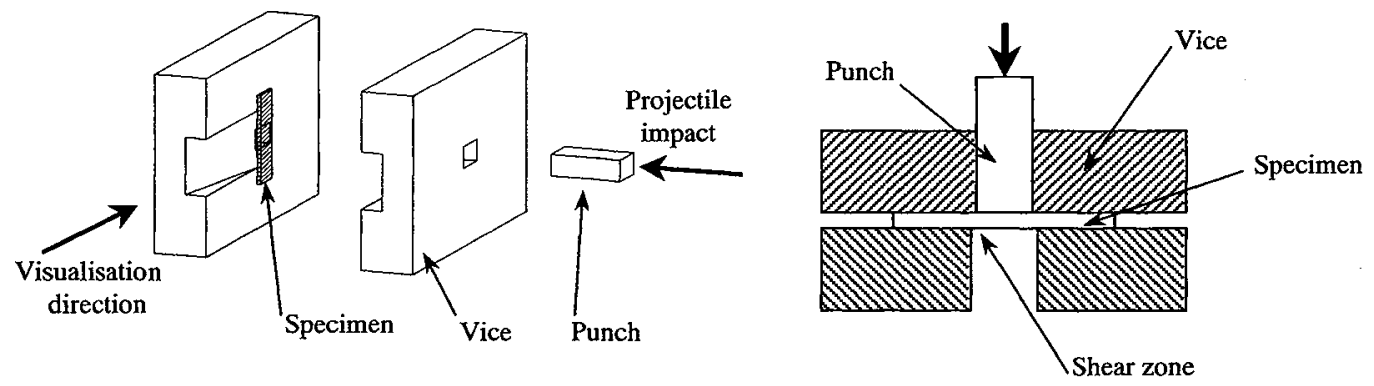

Figure 1: Punching device

\subsection{Pyrometric measurement}

The optical technique of pyrometry is based on the study of the specimen radiation in the shear zone. Our measure system carries out two simultaneous measurements at two distinct wavelengths [3] [4]. With this technique, we can determine the local real temperature of surface and detect the possible phase transition in the shear band.

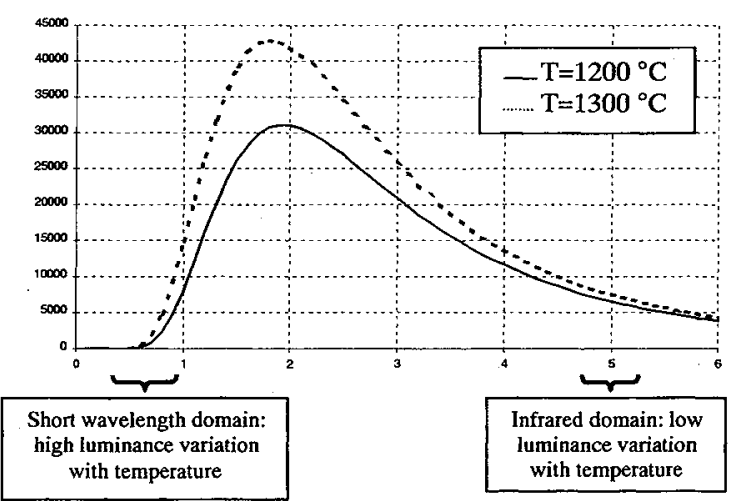

Figure 2: Luminance variation with temperature (Short wavelength domain and infrared domain)

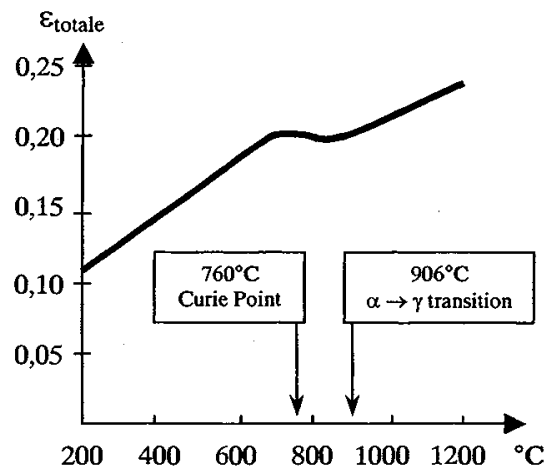

Figure 3: Emissivity variation during phase transition in iron [5] 


\subsubsection{Temperature measurement}

The real temperature of surface is determined by optical pyrometry at short wavelength $(\lambda=0,634 \mu \mathrm{m})$. Measurement is carried out with the shortest possible wavelength in order to minimise the emissivity variation effects. In short wavelength domain, temperature variation induces high luminance variation and the emissivity variation can be neglected (figure 2). One thermography is obtained during the formation of the adiabatic shear band using an intensified CCD camera with a space resolution of about $5 \mu \mathrm{m}$ (size lower than the width of the band). The field of the camera is of $3 \mathrm{~mm} \times 4 \mathrm{~mm}$.

\subsubsection{Phase transition measurement}

On the other hand, infrared luminance is very sensitive to the emissivity variations. In infrared domain temperature variation induces low luminance variation and emissivity variation become major (figure 2). Luminance evolution is measured with an infrared detector. The response time of this detector being about $500 \mathrm{~ns}$, it's possible to study its evolution during the phenomenon. The resolution is then $250 \mu \mathrm{m}$.

The variations of the surface emissivity depends on its temperature, its roughness (during deformation, we can have an evolution of the roughness) and the possible phase transition of material.

Thus, a phase transition can be detected because the variation of the electronic state affects characteristically the emissivity. Drude models for metals show that the material optic and electric properties are bound. In previous work [5], an inflexion point at the phase transition temperature (figure 3 ) is observed on some curves representing emissivity versus temperature.

\section{RESULTS}

\subsection{Different materials}

Two types of titanium alloys will be tested: the TA6V and Ti20V. The figure 4 gives the composition of each alloy.

\begin{tabular}{|c|c|c|c|c|c|}
\hline Weight $\%$ & Al & V & Fe & C & O \\
\hline TA6V & $5,72 \%$ & $4,04 \%$ & $0,147 \%$ & $0,034 \%$ & $0,08 \%$ \\
\hline Ti20V & - & $20,70 \%$ & $0,055 \%$ & $0,030 \%$ & $1000 \mathrm{ppm}$ \\
\hline
\end{tabular}

Figure 4: Composition of the titanium alloys (TA6V and Ti20V)

Pure titanium undergoes an allotropic transformation from hcp (Ti $\alpha)$ to bcc (Ti $\beta)$ as its temperature is rised through $882^{\circ} \mathrm{C}$. At room temperature, the TA6V is a $\alpha+\beta$ alloy which support a mixture of $\alpha$ and $\beta$ phases (figure 6). In the titanium/aluminium equilibrium phase diagram, we can determine that the $\beta(\alpha$ $+\beta$ ) transus is at approximately $955^{\circ} \mathrm{C}$ (figure 5).

On the contrary the Ti20V is a $\beta$ alloy which have sufficient $\beta$ stabilisers element (vanadium) to ensure the retention of the bcc phase on rapid cooling to room temperature (figure 6) [7]. So, during a heating process, the Ti20V don't have a phase transition. 


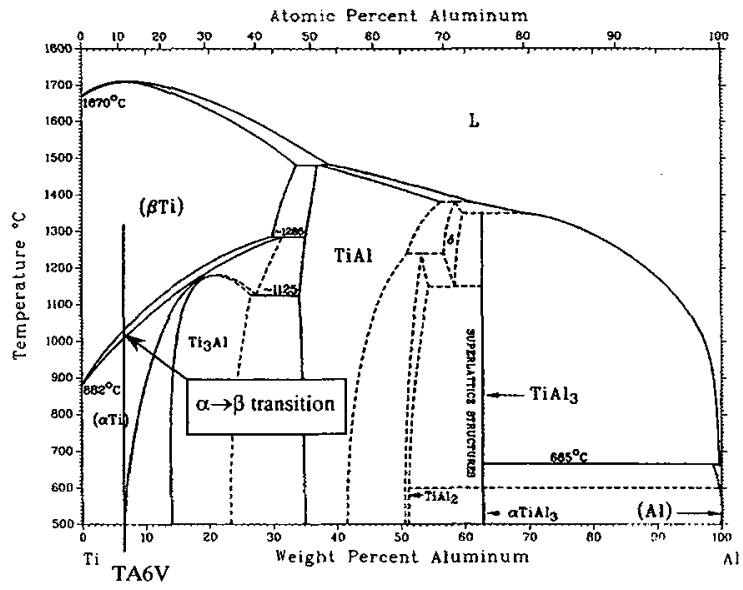

Figure 5 : Titane aluminium binary diagram [8]

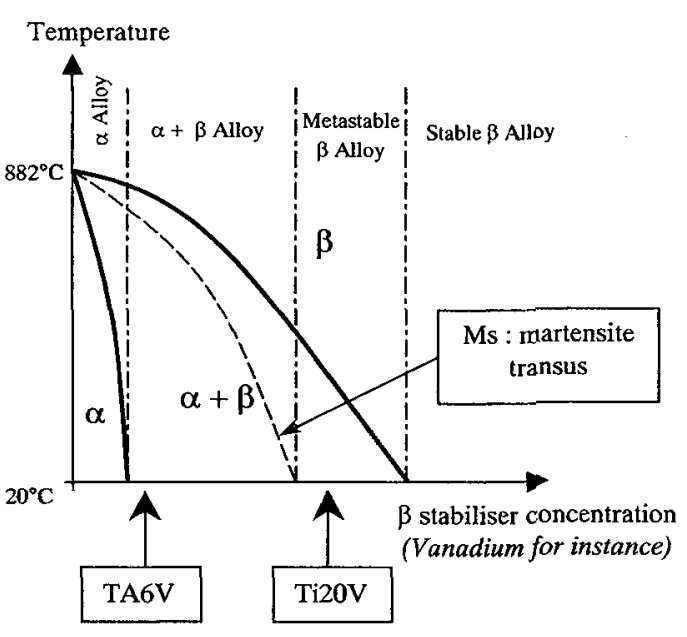

Figure 6 : Pseudobinary phase diagram

\subsection{Temperature measurement}

The tests were carried out for speed of projectile of about $50 \pm 3 \mathrm{~ms}^{-1}$. The figure 7 gives an example of an adiabatic shear band thermography in TA6V. The exposure duration is $6 \mu \mathrm{s}$ and the maximum temperature is $1273^{\circ} \mathrm{C}$. Temperature measurements at different stages of the band's evolution can be obtained thanks to the adjustment of the release of the short wavelength camera (figure 9).

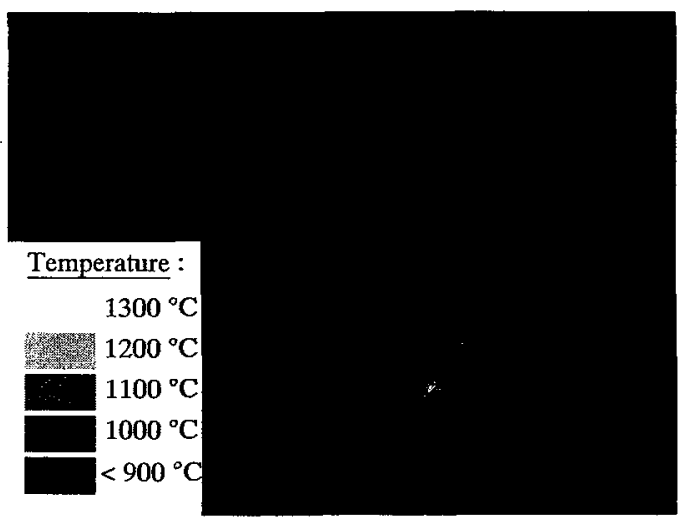

Figure 7: Thermography of an adiabatic shear band

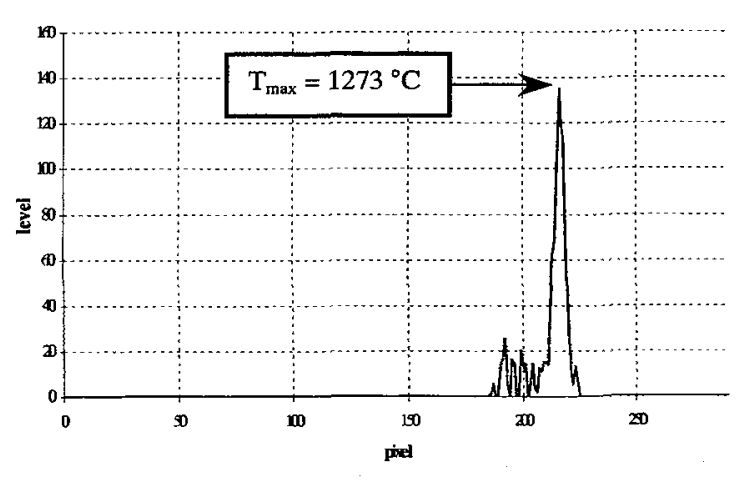

Figure 8: Distribution of the camera level in the band

\subsection{The phase-change measurement}

The graphs in figure 9 and 10 show the infrared signal emitted by the band versus time. The figure 9 represents the temperature in the adiabatic shear band measured using two thermographies at two different stages of its evolution. 
On the figure 10, we can compare the evolution of the infrared signal for two different titanium alloys: the TA6V and Ti20V. All tests were performed at the same projectile velocity $\left(50 \pm 3 \mathrm{~ms}^{-1}\right)$.

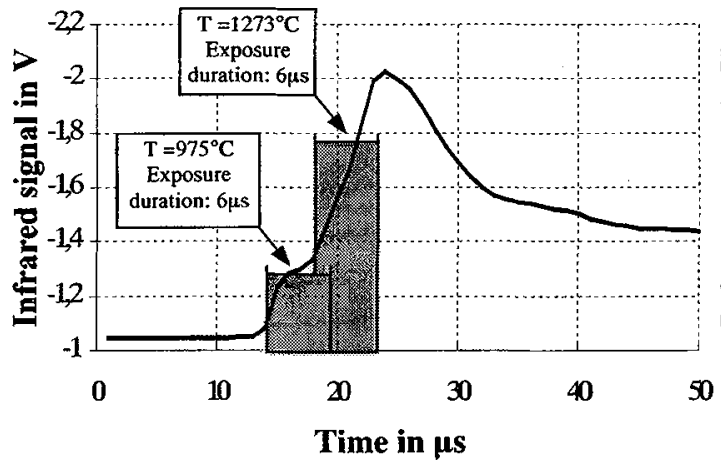

Figure 9: Temperature measures at different stage of the adiabatic shear band's formation

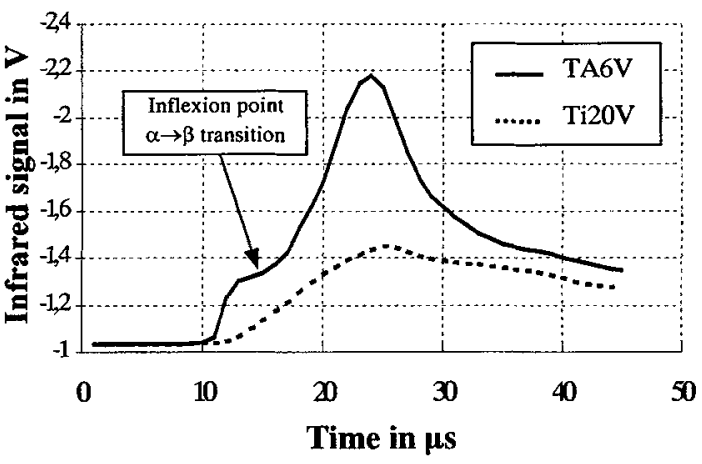

Figure 10: Comparison of infrared signal for two titanium alloys

\section{CONCLUSION}

The distribution of the temperature is localised in one hot spot. In spite of the relatively important time of opening of the camera $(6 \mu \mathrm{s})$, the temperatures observed remain high: They are about $0,8 \mathrm{Tf}$ (Tf: melting point of the TA6V is $1650^{\circ} \mathrm{C}$ ).

The infrared signal depends at the same time on the temperature and the surface emissivity. In the case of the TA6V and Ti20V, it is characterised by an increase of the infrared signal corresponding to an intense heating and a reduction corresponding to a very fast cooling. We can notice that the amplitude of the infrared signal is nevertheless lower in the case of Ti20V.

In the case of the TA6V, we may underline an inflexion point during the heating stage on the graph representing the infrared signal according to time. A study at this stage with the short wavelength pyrometry technique give us a temperature measurement of $975 \pm 68^{\circ} \mathrm{C}$ (Figure 9). It seems that the point of inflection fits the $\alpha \rightarrow \beta$ transition phase of the TA6V. Tests on the Ti20V show the same type of infrared curve but without inflexion point.

\section{PROSPECT}

Taking into account the duration of the heating stage during the phenomenon (about $15 \mu \mathrm{s}$ ), if we want to increase the measure accuracy it would be necessary to reduce the exposure duration of the camera $(<1 \mu \mathrm{s})$. We think, that such an improvement of the device would provide even more important temperatures.

On the other hand, for a better interpretation of the infrared signal, it would be particularly interesting to study the variations of the emissivity with the temperature in the case of the TA6V.

\section{Acknowledgements}

We thank the DGA/CTA for providing the titanium alloy Ti20V. 


\section{References}

[1] Y. BAI and B. DODD, Adiabatic shear localization Occurrence, Theories and Applications (Pergamon Press, 1992)

[2] M.A MEYERS, G. SUBHASH, B. K. KAD and L. PRASAD, Mechanics of Materials 17 (1994) 175193

[3] V. PINA, "Mesure de température de bandes de cisaillement adiabatique dans des alliages de titane", Thesis, University of Paris X, France (1997)

[4] V. PINA, A. RIGUET, P. HERVE and P. MULLER "Opto-thermal characterization of adiabatic shearing bands. Application to TA6V alloy" Proceedings of the $2^{\text {nd }}$ International Symposium on Thermal Stresses and Related Topics, New York, USA, June 8-11 1997

[5] B. PIRIOU, "Mise au point sur les facteurs d'émission", Rev. Int. Htes Temp. et Réfract. T 10 (1973)

[6] A. ZUZIOBEK, V. PINA, P. HERVE, F. DURAND, High Temperature and Materials Science 37 (1997) 97-114

[7] J. P. GUIBERT "Caractérisation microstructurale et mecanique de l'alliage Ti20V" Rapport ETCA 94 R 110, décembre 1994

[8] "Binary alloy phase diagram" $2^{\text {nd }}$ Edition, ASM International 